\title{
An Agile Approach to Glocal Enterprise Collaboration
}

\author{
Frank Lillehagen ${ }^{1}$, Sobah A. Petersen ${ }^{2}$, and John Krogstie ${ }^{2}$ \\ ${ }^{1}$ Commitment AS, Strandveien 30, 1327 Lysaker, Norway \\ Frank. lillehagen@ commitment.no \\ ${ }^{2}$ IDI, NTNU, Høgskoleringen 1, 7491 Trondheim Norway \\ \{sap, Krogstie\} @idi.ntnu.no
}

\begin{abstract}
Effective industry and public project planning, design and execution are increasingly dependent on instant collaboration to deal with unexpected situations and events, caused by nature, technology or people. Agile approaches to enterprise design, responding to growing variety, emergence and complexity of sectors are being researched. This paper presents an agile approach, and illustrates its potential through reporting from pilots and case studies. Agile model-based and architecture-driven solutions have been prototyped. These have a potential for removing interoperability barriers, managing dependencies and complexity, enabling iterative design and smart adaptive operations of products and services. Instant collaboration is triggered by parameters and rules linking affected workspaces, and enabled by architecture-driven knowledge spaces integrated in a visual role-oriented and adaptive work environment. Local practices and work-centric context as well as global context are captured.
\end{abstract}

Keywords: Instant Collaboration, Active Knowledge Architecture, Holistic Design, Architecture-driven Solutions and Knowledge Modeling Methods.

\section{Introduction}

Business, project and solution developers, managers, architects and users are faced with domain-specific layered approaches, where each layer is divided in stages dominated by single disciplines linked by gateways, and supported by chained application software systems. Gateways are used to control progress and manage the handover of information to other teams by delivering a standardized set of documents. When collaboration is not within the organization, but integrates resources across organizations in supply networks, extended enterprises [13] and digital ecosystems [5], the limitations of this approach become obvious. What is missing in current ICT landscapes is an integrated, holistic view on data, their dependencies and derived rules across the full process and product lifecycles. Design and engineering of products and processes are decoupled from the actual execution and product use. A tight integration of all traditional tools used throughout a product lifetime is not feasible. Collaboration, property management, knowledge sharing, dynamic viewing, solution reuse, and competence transfer among stakeholders are severely limited.

Instant collaboration to support project and product design and enable iterative work execution will simplify project and work management, and enable traceability 
and predictability, and decision support. Instant collaboration means that users taking on roles and performing assigned tasks can decide when to involve other roles and users in executing work, managing performance parameters and sharing knowledge.

Agile, role-oriented approaches supporting holistic design, responding to growing variety, emergence and complexity of markets, regions, and companies are being researched. In section 2 we provide more on the needs of future organizations. In section 3 our agile approach, based on architecture-driven solutions, is presented. Five prototypes are available for demonstrations and we present one of these in section 4, before pointing to further implications in section 5. Section 6 holds the conclusions.

\section{Background and Identified Needs}

Present collaborations are to a large extent pre-planned among roles and partners, and supported by static software tools. This is dependent on collaboration taking place in known environments with predefined contexts, such as synchronized timing of exchanges and contributions. In e.g. the EU project LinkedDesign [14] the support of more dynamic situations of collaborative engineering in a Virtual Obeya [6], a collaborative work environment [12], is experimented with. But this work is still in an early stage. Instant collaboration, enhancing and exploiting human mental models [2], is an agile approach to enterprise knowledge architecture and holistic design of enterprises, balancing parameters and dependencies. Knowledge modelling and management must be performed by role-oriented teams involving practitioners, applying conceptual, fine-grained graphic languages to capture emerging knowledge.

Fine-grained graphic languages were conceived as the solution to agile modelling and executable models as early as 1994 [7]. Enterprise methodologies will become knowledge models and active elements in emergent Enterprise Architecture (eEA), enabled by agile workplaces for enterprise design. An agile workplace is influenced by tasks performed and data created by users at any other workplace. To enterprise managers, the CTO and CIO in particular, this means that a deeper understanding of role-oriented workspaces, visual knowledge models, model-based workplaces and visual modelling methods are needed. Smart networked enterprises cannot be built by acquiring or developing application software systems alone, and adaptive services cannot be delivered by current methods. Future development, use and value of ICT will be managed by sharing situated enterprise knowledge and reusing role-oriented workspaces and architecture-driven workplaces as illustrated in Fig 1.

The nature of enterprise knowledge spaces and workspaces must be conceived by users applying graphical modeling to capture work-centric context in an active knowledge architecture. The resulting enterprise platform will support customerdriven solutions and situation-driven operations. Knowledge and experience sharing will be facilitated and knowledge assets will be decisive for future competitiveness and progress. Collaboration has traditionally been supported by process modelling [3] and the setting up of synchronized events [8]. With new demands for customer, partner and supplier involvement and support of holistic design [9] we must support the execution of instant collaborative design, team-building and project planning and execution. New competences are needed as illustrated in Fig.1 and Fig.2. 


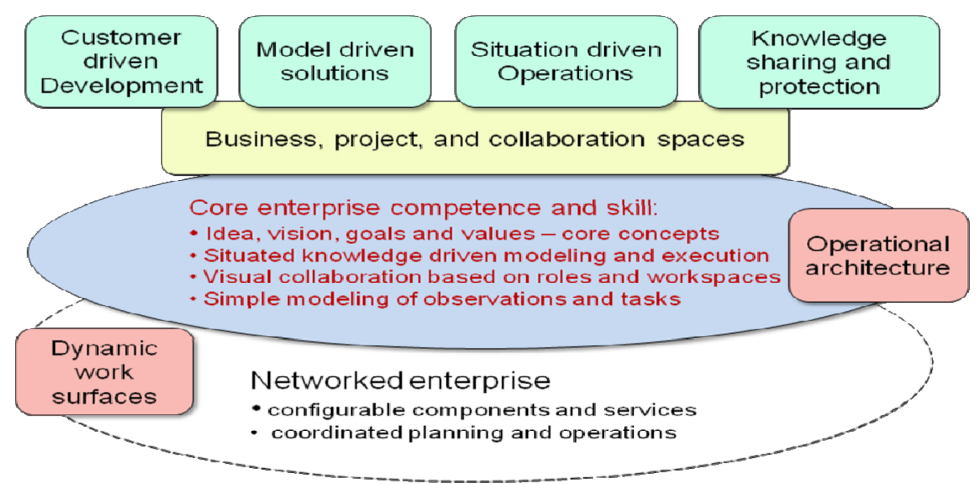

Fig. 1. New ICT enabled enterprise concepts, approaches, methods and solutions

Conceptual design of projects and products are currently poorly supported by static ICT solutions. Graphic language constructs allowing users to define tasks, data and emerging values are missing. This gap in the design life-cycle must be filled. Present life-cycles are linear and rarely support collaboration and iterations as they are dealing with physical artifacts, and material or document flows.

To support future networked enterprises we must meet the following needs:

1. Collaborative Enterprise Networking for participation in multiple networks.

2. Self-developing organizations for role-based learning and competence transfer.

3. Agile autonomous methods for communication, collaboration, visualization, knowledge sharing and enterprise readiness.

4. Emergent Enterprise Architecture for handling dependencies, traceability, predictability, adaptation, alignment and change.

5. Powerful data capture for analyses, and domain modelling and aggregation for developing new knowledge.

6. Federated product models for transparent co-design, flexible manufacture and in-use modifications.

7. Communities of Practice and Learning [15] for transferring competence.

8. Front-end loading of project knowledge architecture (base), for effective reuse of knowledge and adaptive solutions.

9. Value-chains with holistic organizations, enabling bottom-up collaborative patterns and knowledge sharing.

10. Designing for emergence, enabling continuous innovation and learning and practical training spaces (the digital apprentice).

In networked enterprise design, product and services delivery, we see the need for agile workplaces driven by Active Knowledge Architecture (AKA) to support instant collaboration and emerging knowledge sharing among teams, as illustrated in Fig. 2:

- Conceptual Design Team; developing new enterprise designs, business models, solution concepts, performing conceptual and holistic project design.

- Architecting Team; building and adapting the active architectures and the common emergent EA, creating and adapting graphic languages and application templates, and accessing reference models (repository of classes). 
- Organization Team; defining and aligning new roles, their model-based workplaces, their access rights and security, and the services and views they require as local and joint contexts evolve.

- Methodology Team; developing methodology for networked enterprise design and development, and organization and life-cycle management.

- Applications Team; developing and validating new services, methods and models, experimenting with alternative approaches, methods and solutions, and supporting continuous learning and innovation.

- Management Team; planning, performing and following up on work/tasks, situations and actions, managing alternatives and supporting decision-making, and recruiting and training personnel to take on roles.

- Knowledge Management Team; developing, maintaining and managing enterprise knowledge and providing services to build the architectures required.

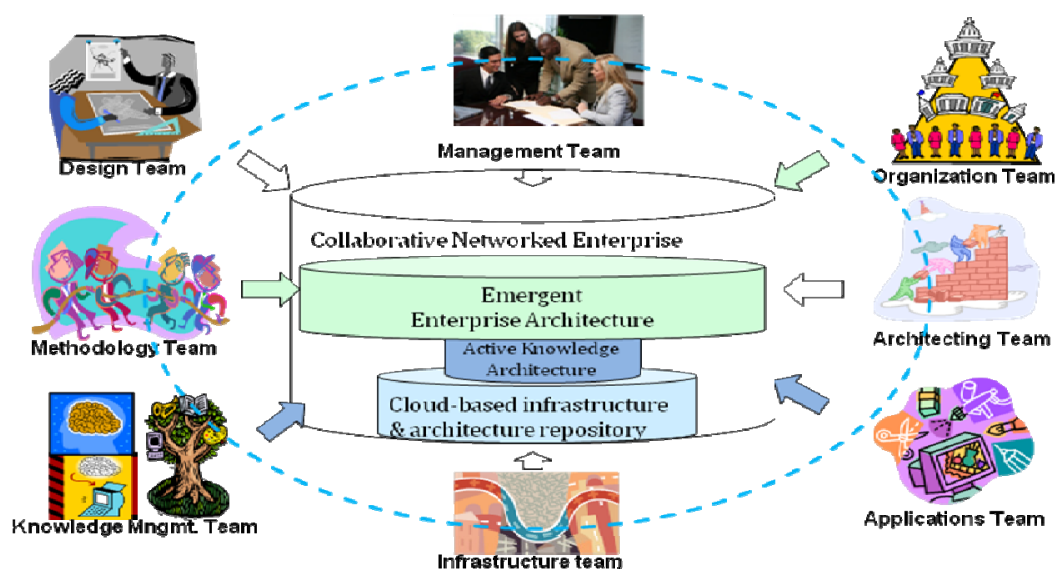

Fig. 2. Core collaborating teams of networked enterprises

\section{Model-Based, Architecture-Driven Solutions}

An agile holistic design approach, based on Active Knowledge Modeling (AKM) [4, 8], provides creative workers and practitioners with model-based workplaces and adaptive visual working environments. Methods and capabilities needed for instant collaboration, knowledge sharing and holistic design can be modelled. The approach will enable agile knowledge architecting, and collaborative learning and innovation, embracing new design and working concepts and methodologies. Challenges faced by industry and public domains to master participation in multiple global projects require an agile holistic design approach and an active knowledge environment enabling role-oriented learning and reuse [4]. Based on the agile approach to building and managing enterprise workspaces, Collaborative Enterprise Architecture (CEA) is envisioned as the core of the next generation enterprise ICT solutions [7], irrespective of public or industrial sector. The agile approach enabled by model-based workplaces 
and architecture-driven solutions, piloted since 2007 [8], is illustrated in Fig. 3. Workplace layout and behaviour is one model (top right) allowing each workplace to be tailored to roles and users. The agile model-based, architecture-driven approach removes existing interoperability barriers, and supports iterative design and emerging operations. Simple fine-grained graphic modelling by users supports data capture and powerful visualization of local work-centric context as well as global dependencies. Agile workspaces and model-based workplaces allow radical cuts in lead-times and expenses, and support the realization of customized smart products and adaptive manufacturing plants, and establish a practical knowledge-base for new projects. Change management will be replaced by traceable iterations and choice among parallel alternative solutions. This will facilitate global project design, knowledge sharing, competence transfer, and new approaches to work management [11].

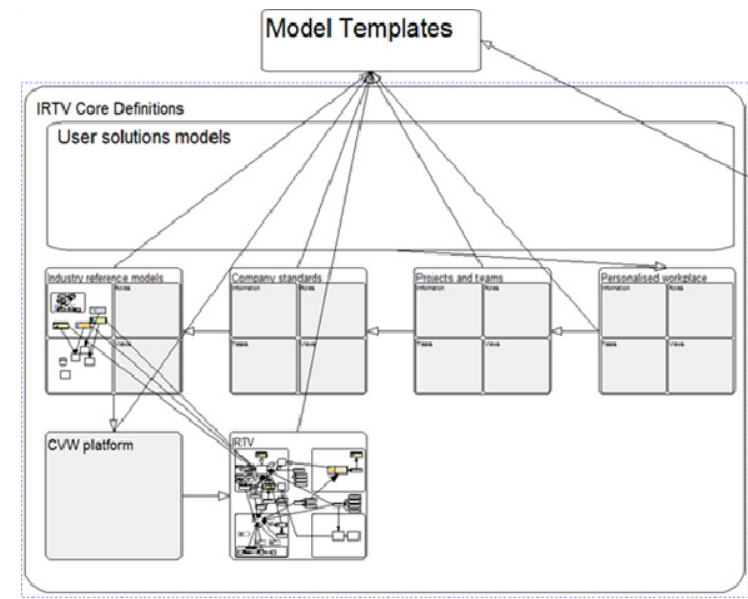

The framework is composed of enterprise knowledge and role-oriented workspace, and workplace models.

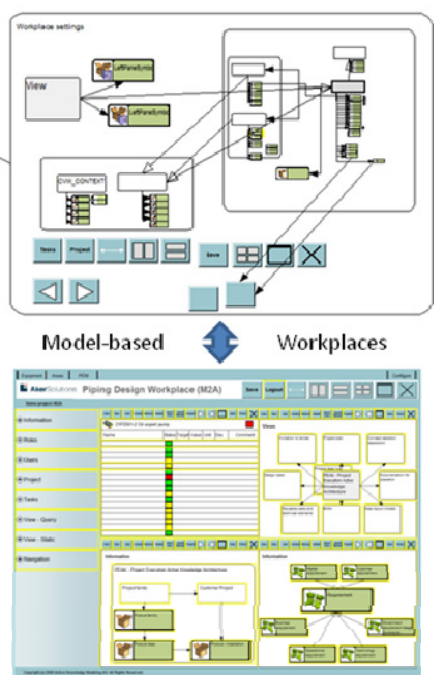

Fig. 3. Knowledge modelling of model-based and architecture-driven workplaces

Agility and emergence is achieved by model-based, architecture-driven workplaces, providing capabilities for extending and modifying the Active Knowledge Architecture (AKA), and to reflect operations across workspaces. A key characteristic of our approach is best summarized as "use visual modelling rather than coding to capture global as well as local context". A second key characteristic is supporting categories of users (e.g. designers and engineers) in capturing events, situations, dependencies, changes, data and local knowledge contexts by building role-oriented workspaces, adaptive models and agile workplaces.

The agile approach will have revolutionary impacts on business approaches, on methodologies, knowledge management and reuse across sectors. ICT development will be performed by distributed teams collaborating to develop knowledge models, composing user services, building federated architectures, and managing future classes, categories and families of enterprise knowledge assets across sectors. 


\section{Industrial Pilots}

We have since 2007 performed five industrial pilots. These pilots demonstrate the feasibility, opportunities, and potential benefits of model-based, architecture-driven solutions and workplaces. One of the pilots focused on new approaches and methods for oil field Engineering, Procurement and Completion - EPC projects [10]. Modelbased architecture-driven holistic design and generation of collaborative workplaces were successfully developed to support the piping manager, piping engineer and the methodology responsible. The early joint architecting workplace is shown in Fig. 3.

A pilot from the MAPPER project [16] highlights the potential of collaborative seat-heating design using shared views of design parameters. The needs of Kongsberg Automotive (KA), the seat-heating producer, are very similar to the needs expressed by companies in other industrial and public sectors, such as aerospace, construction, transport and energy supply. In short, the needs and goals were to:

- Capture and correctly interpret customer requirements and preferences,

- Create role-specific, simple to use and re-configurable workplaces,

- Create effective shared workplace views and services for parameter balancing,

- Improve the quality of specifications and design for customers and suppliers,

- Improve communications, collaboration and coordination among stakeholders,

- Find a good methodology for product design, using task-patterns for automating most of the customized product design and engineering.

To fulfil these goals, KA decided on investigating the AKM approach, adapting several methodologies and building model-based workplaces. Material specifications are the core knowledge of collaboration between the seat manufacturer, the seatheating producer represented by KA, and the supplier represented by Elektrisola (E). The material specification is today managed as a document, typically created in Microsoft Word. The content in a specific version of the material specification is put together by one person at KA and approved by E and both companies are filing one copy of the approved material specification. Over time, additional customer requirements and changes need to be communicated, resulting in new parameter values in new versions of the document. The most serious disadvantages are:

- The content in the material specifications is not easily accessed and cannot contribute to the two companies' operations directly.

- The process and work logic to achieve a consistent specification is not captured, making integration with other processes impossible.

- The involvement and commitment from the supplier is not encouraged, there is no support for mutual adjustments in supply and demand. Keeping the material specifications updated in both companies can be quite time consuming.

The proposed approach was to replace the document with an operational visual knowledge environment supporting dynamic viewing and knowledge sharing. The environment developed was enabled by an active knowledge architecture built by using the Configurable Visual Workplace module developed with AKM-technology [8]. The main advantages with the model-based knowledge architected solutions are:

- The content in the material specifications will be easy to access by both companies and can be part of the each company's complete knowledge 
architecture, provided that the model-based solution is replacing the document based solution for other applications within the companies.

- The involvement from supplier E and other suppliers will be encouraged and the supplier commitments will be more obvious and traceable.

- The time for agreeing on the best seat-heating design alternative, considering also the material specification and the seat manufacturing process, is reduced to days. There is no real need of filed paper copies anymore.

\section{$5 \quad$ Contributions to Sustainable Reindustrialization}

The model-based, architecture-driven solutions design and delivery is ideal for what is described as the reindustrialization of western industries. Instant collaboration, open innovation [1], workplace training and learning and rapid competence transfer and adaptation to new environments and situations are just a few of the demands mentioned in section 2. As illustrated in Fig. 4, the common approach, methods, infrastructures and solutions to all industrial and public enterprises can be composed by the Architecting team applying fine-grained modelling methods.
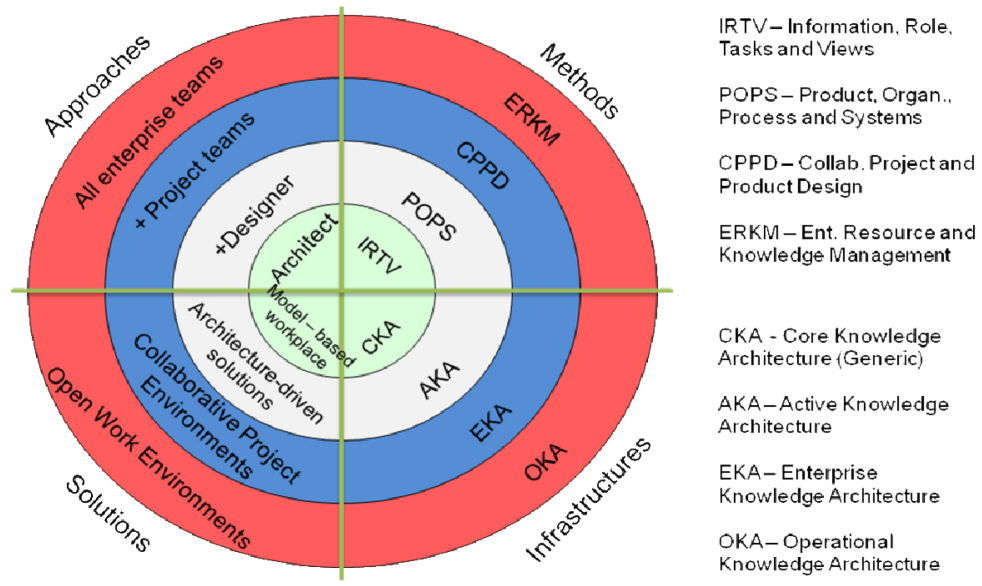

Fig. 4. Spaces of emergent approaches, methods, infrastructures and solutions

The Core Knowledge Architecture (CKA) meta-meta model, the generic IRTV language constructs, the Architect workplace and core services, and the agile approach are common to all sectors and solutions. Adding designer and user teams, extending modelling language and methods to capture aspects of Product, Organization, Process and System (POPS), enabling the design of sector specific methods, architectures and solutions. Architecture-driven solutions will enhance present PLM solutions with capacities similar to the seat-heating case. In the third space, adding more project teams, adapting components of the CPPD methodology [8], the teams are able to start focusing sector specific solutions, and adding classes and categories of enterprise knowledge assets to support sustainable life-cycles. 


\section{Conclusions}

To meet the rapidly growing challenges and opportunities, industry and public sectors are in urgent demand for new ways of providing and applying computing power. We believe the AKM technology has the concepts, capacities and properties required to provide this new way of computing. Future work will focus on developing and providing sector and life-cycle specific agile approaches, holistic design and analysis methods, knowledge architectures and open AKM-platforms. These will be enhanced and extended through applications in both the private and public sectors.

We will build partner networks for AKM Platform component development and platform composition, operation and support, and for methodology modeling and integration. Partner networks for Collaborative Learning and Training, and for Open Innovation and Experimentation will be established to promote the approach and help SMEs and private people in joining business, training and other networks.

\section{References}

1. Chesbrough, H.: Open Services Innovation. Rethinking your business to growth and compete in a new era. Jossey-Bass, San Francisco (2011)

2. Craik, K.: The Nature of Explanation. Cambridge University Press (1943)

3. Houy, C., Fettke, P., Loos, P., van der Aalst, W.M.P., Krogstie, J.: BPM-in-the-Large Towards a higher level of abstraction in Business Process Management. Paper Presented at the Accepted at GISP under WCC (2010)

4. Jørgensen, H., Lillehagen, F.: Content of the Active Knowledge Modeling blog, http: / / activeknowledgemodeling.com/

5. Krogstie, J.: Modeling of Digital Ecosystems: Challenges and Opportunities. In: Camarinha-Matos, L.M., Xu, L., Afsarmanesh, H. (eds.) Collaborative Networks in the Internet of Services. IFIP AICT, vol. 380, pp. 137-145. Springer, Heidelberg (2012)

6. Krogstie, J.: A Semiotic Approach to Data Quality. In: Nurcan, S., Proper, H.A., Soffer, P., Krogstie, J., Schmidt, R., Halpin, T., Bider, I. (eds.) BPMDS 2013 and EMMSAD 2013. LNBIP, vol. 147, pp. 395-410. Springer, Heidelberg (2013)

7. Lillehagen, F., Krogstie, J.: Active Knowledge Modeling of Enterprises. Springer (2008)

8. Lillehagen, F., Krogstie, J., Petersen, S.: Active Knowledge Architecture; What Systems Engineering Need to Embrace, paper in SE Newsletter. SYEN 47 (http://

9. Larson, T.: Enabling Collaborative Enterprise, http: //mindjet. com/blog/

10. Lillehagen, F., Petersen, S.A., Krogstie, J.: Enabling Holistic Design, Innovation and Learning. In: The XXIII ISPIM Conference - Action for Innovation: Innovating from Experience, June 17-20 (2012)

11. Wang, W., Lillehagen, F.M.: A cooperative hypermedia solution to work management in real-time enterprises. In: Hypertext 2003, pp. 196-197 (2003)

12. Aasland, K., Blankenburg, D.: An analysis of the uses and properties of the Obeya. In: Proceedings of the 18th International ICE-Conference, Munich (2012)

13. Jagdev, H.S., Brown, J.: The Extended Enterprise - A Context for Manufacturing. International Journal of Production Planning and Control 9(3), 216-229 (1998)

14. LinkedDesign, Linked Knowledge in Manufacturing Engineering and Design for NextGeneration Production (2012), http://www.linkeddesign.eu/ (retrieved April 23, 2013)

15. Wenger, E.: Communities of Practice: Learning, Meaning, and Identity. Cambridge University Press (1998)

16. Sandkuhl, K., Lillehagen, F.: The Early Phases of Enterprise Knowledge Modelling: Practices and Experiences from Scaffolding and Scoping (2008) 